TITLE:

\title{
Model for charging/discharging dynamics of cells in redox flow battery with transport delay
}

$\operatorname{AUTHOR}(S)$ :

Mannari, Toko; Okuda, Takafumi; Hikihara, Takashi

\section{CITATION:}

Mannari, Toko ... [et al]. Model for charging/discharging dynamics of cells in redox flow battery with transport delay. Physica Scripta 2019, 94(9): 095005.

\section{ISSUE DATE:}

2019-09

URL:

http://hdl.handle.net/2433/267520

\section{RIGHT:}

This is the Accepted Manuscript version of an article accepted for publication in 'Physica Scripta'. IOP Publishing Ltd is not responsible for any errors or omissions in this version of the manuscript or any version derived from it. The Version of Record is available online at https://doi.org/10.1088/1402-4896/ablacd.; The full-text file will be made open to the public on 10 July 2020 in accordance with publisher's 'Terms and Conditions for Self-Archiving'.; This is not the published version. Please cite only the published version.この論文は出版社版でありません。引用の際には出版社版を ご確認ご利用ください。 


\title{
Model for charging/discharging dynamics of cells in redox flow battery with transport delay
}

\author{
Toko Mannari ${ }^{1}$, Takafumi Okuda ${ }^{2}$ and Takashi Hikihara ${ }^{3}$ \\ Department of Electrical Engineering, Kyoto University, Nishikyo Katsura, Japan \\ E-mail: t-mannari@dove.kuee.kyoto-u.ac.jp ${ }^{1}$, \\ t-okuda@dove.kuee.kyoto-u.ac.jp ${ }^{2}$, hikihara.takashi.2n@kyoto-u.ac.jp ${ }^{3}$
}

August 2018

\begin{abstract}
A redox flow battery (RFB) is an energy storage capable of contributing to grid balancing under the fluctuation of renewable power sources and loads. An RFB consists of reaction cells and tanks containing electrolytes that are pumped to the cells. Modeling of the charging/discharging dynamics is necessary for controlling the flows of the electrolytes and the current. The previous researches have assumed that the transport delay is small and negligible. However, when the transport delay appears, it affects the performance of the control systems. This paper aims to propose a model for considering charging/discharging dynamics with transport delay. The delay appears in the voltages of the cells in the tested system, and a model is introduced to simulate the delay. The model is represented by delay differential equations (DDEs) of the ion concentration in the cells with the Nernst relationship. The DDEs are derived from the mass balance equation including the transport delay translated to the time delay. The simulation result excellently agrees well with the experiment at results. In other words, the model can predict the dynamics governed by the transport delay accurately.
\end{abstract}

Keywords: Redox flow battery, Modeling, State-of-charge, Nernst equation, Delay differential equation, Transport delay

\section{Introduction}

Redox flow batteries (RFBs) [1] have attracted research attentions as energy storage in power grids [2, 3]. An RFB consists of cells and tanks. Each of the loaded cells (main cells) exchanges electric power and chemical potential through the membrane which separates the positive and negative electrolytes. A tank keeps the chemical potential as the form of ions in the positive or negative electrolyte. The positive electrolyte circulates between the positive tank and the positive side of the cells by pumping, and vice versa. RFBs show quick response and keep the long term operation [3, 4], simultaneously. Therefore, they are applicable to both high power and high energy operation $[5,6]$. The former aims to regulate the frequency of electrical power and to compensate for voltage 
sag, and the latter deals with load leveling and peak shifting. Power grids require energy storages which can satisfy both operations depending on the characteristics of the loads. That is, RFBs are the candidate to satisfy this requirement.

The current of the external circuit and the flow rate of electrolyte in the internal fluid circuit are the dominant parameters at the transient. The parameters govern the evolution of ions in the cells, which decides the electric output power of the RFB and the state-of-charge (SOC) of the cells. Controlling the parameters is directly connected to the operation of RFBs $[7,8,9]$. A precise model of transient dynamics is essential for the design of an effective control method.

There have been developed the dynamical models of the RFBs based on the chemical reactions and the mass transfer in the cells $[10,11,12,13]$. The models have promoted the discussion of the charging/discharging dynamics associated with the parameters. Among them, the flow rate of the electrolytes is substantial. Li et al. derived a simple dynamical model of the RFB based on the oxidation-reduction reaction and the advection in the cell [11]. Simulation with this model gives us some directions about flow control systems [14]. The phenomena inside of cells are considered in more detail $[12,13]$, for example, the side reaction and the diffusion of the ions.

The charging/discharging dynamics are also governed by the mass transport via the pipes and the stay in the tanks, which occur out of the cells. They depend on the finite speed of the electrolyte flow and causes the delay in the dynamics [15]. However, the previous modeling researches have mostly neglected the delay derived from the fluid circuit. Especially, the transport delay has not been considered. The delay has already been observed from the voltages of the cells $[11,16]$. The transport delay is a critical issue in the control systems for the fluid system like the district heating system [17] and the exhaust gas recirculation engine [18]. The delay can affect the performance of the control systems $[19,20]$. Therefore the consideration of the transport delay is inevitable for the design of the flow control system.

This paper proposes a dynamical model of the RFB including the transport delay and verifies the model with a tested system. Chapter 2 explains the delay in the charging/discharging dynamics of the cells. Moreover, the two kind of the delays are estimated from the voltages of cells in the tested system. Based on the measurement, chapter 3 proposes a model to simulate the delays appeared in the voltages of the cells. The model is represented by delay differential equations (DDEs) [21] of the ion concentration in the cell and the Nernst relationship. The DDEs are derived from the mass balance equations [22] due to mass the transport via the pipes as the time delay. The model shows an excellent agreement with the experiment and well prediction of the delays. 


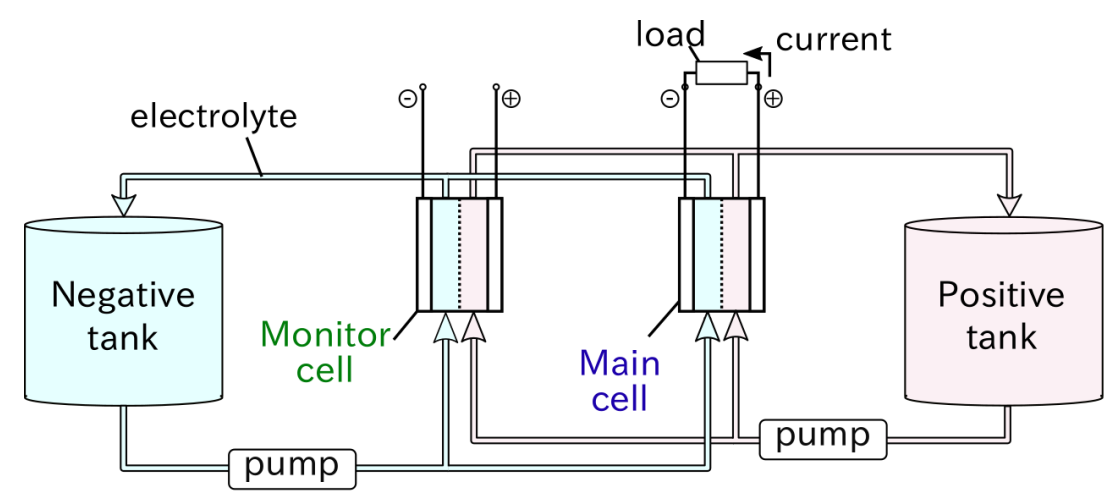

Figure 1. RFB equipped with a monitor cell. The oxidation-reduction reaction occurs in the main cell. The electrolytes are stored in the tanks. The OCV is observed from the monitor cell.

\section{Voltages of cells}

\subsection{RFB system configuration}

Figure 1 shows an RFB system equipped with a monitor cell [23, 24]. The electrolytes flow from the tanks into the pipes, which lead to the main cell and the monitor cell.

The following oxidation-reduction reaction [1] in the main cell changes the chemical potential into an electrical potential.

$$
\left\{\begin{array}{lr}
\mathrm{V}^{2+} \rightleftharpoons \mathrm{V}^{3+}+\mathrm{e}^{-} & \text {(Negative electrode) } \\
\mathrm{VO}_{2}^{+}+2 \mathrm{H}^{+}+\mathrm{e}^{-} \rightleftharpoons \mathrm{H}_{2} \mathrm{O}+\mathrm{VO}^{2+} & \text { (Positive electrode) }
\end{array}\right.
$$

The reaction (1) is accompanied by the transfer of protons across the ion exchange membrane as follows.

$$
\left.\mathrm{H}^{+}(\text {Negative half cell }) \rightleftharpoons \mathrm{H}^{+} \text {(Positive half cell }\right)
$$

The supply of ions from the tank sustains the reaction (1).

The monitor cell has the same structure as the main cell. There will not appear any oxidation-reduction reactions in the monitor cell. The open-circuit voltage (OCV) is measured from the open port of the monitor cell. The monitor cell has been set in the fluid circuit for the SOC estimation of the main cells [23, 24]. The symbols are listed in Table 1.

\subsection{Delay in state estimation with monitor cell}

The SOC estimation using the monitor cells requires the assumption for the state of the ions in the cells. This assumption neglects the mass transport via the pipes and the stay in the tanks. However, the delays derived from the fluid circuit is not negligible and contradict to the assumption for the SOC estimation. This section reconsiders the condition for the SOC estimation with the delay derived from the fluid circuit.

The OCV of a cells is determined by the concentration of ions in the electrolyte based on Nernst relationship [25]. Hereafter we call the relationship the Nernst equation. 
Table 1. Nomenclature.

\begin{tabular}{|c|c|c|}
\hline$E_{\mathrm{e}}$ & Open-circuit voltage $(=g(c))$ & $\mathrm{V}$ \\
\hline$c$ & Concentration of $\mathrm{V}^{2+}$ or $\mathrm{VO}_{2}^{+}$ & $\operatorname{mol~L}{ }^{-1}$ \\
\hline$c_{\text {main }}$ & Concentration of $\mathrm{V}^{2+}$ or $\mathrm{VO}_{2}{ }^{+}$in main cell & $\operatorname{mol~L}{ }^{-1}$ \\
\hline$c_{\text {monitor }}$ & Concentration of $\mathrm{V}^{2+}$ or $\mathrm{VO}_{2}{ }^{+}$in monitor cell & $\operatorname{mol~L}{ }^{-1}$ \\
\hline$V_{\text {main }}$ & Total voltage of main cells & $\mathrm{V}$ \\
\hline$V_{\text {monitor }}$ & Voltage of monitor cell & $\mathrm{V}$ \\
\hline$\Delta V$ & Difference in voltage $\left(=V_{\text {main }} / m-V_{\text {monitor }}\right)$ & $\mathrm{V}$ \\
\hline$\Delta c$ & Difference in ion concentration $\left(=c_{\text {main }}-c_{\text {monitor }}\right)$ & $\operatorname{mol~L}{ }^{-1}$ \\
\hline$N$ & Molar amount of $\mathrm{V}^{2+}$ or $\mathrm{VO}_{2}^{+}$in $\mathrm{RFB}$ & mol \\
\hline$R$ & Gas constant & $\mathrm{J} \mathrm{K}^{-1} \mathrm{~mol}^{-1}$ \\
\hline$T$ & Temperature & K \\
\hline$F$ & Faraday constant & $\mathrm{C} \mathrm{mol}^{-1}$ \\
\hline$E_{\mathrm{e}}^{0}$ & Standard electrode potential & $\mathrm{V}$ \\
\hline$E_{\mathrm{eh}}^{0}$ & Open-circuit voltage at $c=c_{\max } / 2$ & $\mathrm{~V}$ \\
\hline$c_{\max }$ & Maximum concentration of vanadium ions in cells & $\operatorname{mol~L}{ }^{-1}$ \\
\hline$m$ & Number of main cells & \\
\hline$I$ & Current (charging : $I<0$, discharging : $I>0$ ) & A \\
\hline$W_{\mathrm{c}}$ & Flow rate of electrolyte in cell & $\mathrm{L}_{\min }{ }^{-1}$ \\
\hline$\alpha_{\mathrm{c}}$ & Volume of electrolyte in cell & $\mathrm{L}$ \\
\hline$\alpha_{\mathrm{t}}$ & Volume of electrolyte in tank & $\mathrm{L}$ \\
\hline$\tau_{\mathrm{c}}$ & Time constant in approximation of $\Delta V$ & $\mathrm{~s}$ \\
\hline$\tau_{\mathrm{d}}$ & Time delay in DDE & $\mathrm{s}$ \\
\hline
\end{tabular}

The Nernst equation gives the equilibrium potential of a process in an electrochemical system. The equilibrium potential of the reaction (1) appears as the OCV of a cell. Proton exchange (2) instantly achieves the equilibrium determined by reaction (1). The potential of reaction (1) decides the OCV as follows (3).

$$
E_{\mathrm{e}}=E_{\mathrm{e}}^{0}+\frac{R T}{F} \ln \frac{\left[\mathrm{V}^{2+}\right]\left[\mathrm{VO}_{2}^{+}\right]\left[\mathrm{H}^{+}\right]^{2}}{\left[\mathrm{~V}^{3+}\right]\left[\mathrm{VO}^{2+}\right]}
$$

Here, it is assumed that the positive and negative half cells keep symmetry in charging/discharging process [11]. The symmetry restricts the ion components in a cell as follows.

$$
\left[\mathrm{V}^{2+}\right]=\left[\mathrm{VO}_{2}^{+}\right]=c,\left[\mathrm{~V}^{3+}\right]=\left[\mathrm{VO}^{2+}\right]=c_{\max }-c
$$

From the restriction, each of the components of the vanadium ions is uniquely determined by the value of concentration, $c \in\left(0, c_{\max }\right)$. The concentration $c$ determines SOC [26]. The variation in the OCV due to protons is negligible [27]. Then, equation 


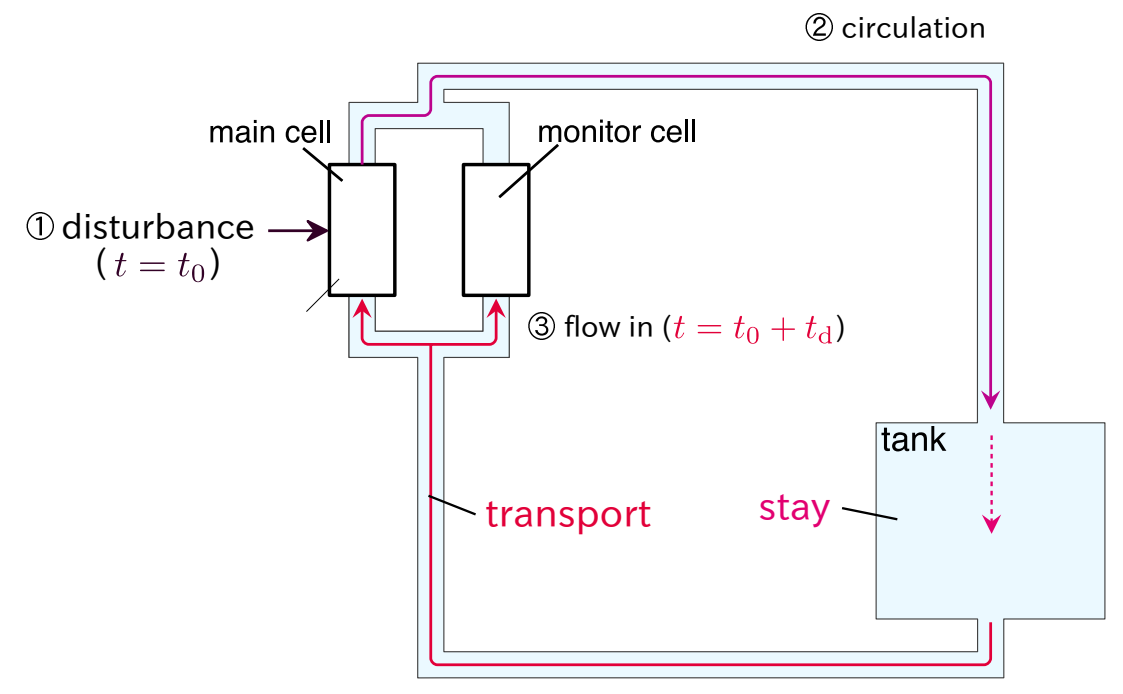

Figure 2. Delay derived from the fluid circuit of the electrolyte. (1) The disturbance occurs in the current at $t=t_{0}$. (2) The electrolyte circulates in the fluid circuit. (3) The effect of the disturbance appears at $t=t_{0}+t_{\mathrm{d}}$.

(3) is simplified via restriction (4) as follows.

$$
E_{\mathrm{e}}=g(c)=E_{\mathrm{eh}}^{0}+\frac{2 R T}{F} \ln \frac{c}{c_{\max }-c}
$$

$g(c)$ gives the OCV of a cell. Here are introduced the critical assumption for estimating the SOCs of the main cells through the OCV of the monitor cell as follows. $\dagger$

$$
\begin{aligned}
& c_{\text {main }} \in \mathbb{A}, \\
& \mathbb{A}=\left\{c_{\text {main }} \in \mathbb{R}|| g\left(c_{\text {main }}\right)-g\left(c_{\text {monitor }}\right) \mid<\varepsilon\right\}
\end{aligned}
$$

The assumption (6) assures that the difference of the ion distribution between the main and monitor cells is small enough not to affect the estimation.

The function $g(c)$ is unique and invertible in $c \in\left(0, c_{\max }\right)$. The ion concentration in the main cells is estimated as follows under the assumption (6).

$$
c_{\text {main }} \approx c_{\text {monitor }}=g^{-1}\left(V_{\text {monitor }}\right)
$$

Here, $V_{\text {monitor }}$ is the OCV of the monitor cell. The voltage drop of the loaded cell depends on the internal resistance on the time scale of seconds. The following relationship is held from the assumption (6).

$$
\begin{aligned}
\Delta V & =\left\{g\left(c_{\text {main }}\right)-r I\right\}-g\left(c_{\text {monitor }}\right) \\
& \approx-r I
\end{aligned}
$$

Where $\Delta V$ is the difference in the voltages of the main cell and the monitor cell. $r$ is the internal resistance of the main cell.

Figure 2 shows the delay derived from the fluid circuit. The disturbance added to the current at $t=t_{0}$ affects the charging/discharging dynamics in all of the cells with $\dagger$ The order of $\varepsilon$ is about $0.01 \mathrm{~V}$ in the experiment. 
Table 2. Setting parameters for experiment.

\begin{tabular}{c|c}
\hline Current $(I)$ & $-50 \mathrm{~A}$ or $50 \mathrm{~A}$ \\
Threshold of $V_{\text {main }}$ & $14.50 \mathrm{~V}$ \\
Number of main cells $(m)$ & 10 \\
Flow rate of electrolyte $\left(W_{\mathrm{c}} \times(m+1)\right)$ & $3.3 \mathrm{~L} \mathrm{~min}^{-1} / 5.5 \mathrm{~L} \mathrm{~min}^{-1}$ \\
Volume of cell & $125 \mathrm{~mL}$ \\
Volume of tank & $10 \mathrm{~L}$ \\
\hline
\end{tabular}

a delay $t_{\mathrm{d}}$. The delay $t_{\mathrm{d}}$ is derived from the mass transport via the pipes and the stay in the tanks. The significant delay appears in the monitor cell because the dynamics of the monitor cell are only governed by the electrolyte flow. It is difficult to satisfy the assumption (6) under the disturbances in the current. The consideration for the delay is essential for estimating the state of the ions in the cells and discussing the dynamics.

\subsection{Voltages of main cells and monitor cell in experiment}

In this section, the voltages of the cells are discussed based on the experimental result obtained in a tested system. The settings of the experiment are listed in table 2. Figure $3(\mathrm{a})$ is the photograph of the tested system. The system consists of an RFB and an external circuit that enables the RFB to charge/discharge at a fixed current.

Figure 3(b) shows the structure of the cell stack in the RFB. The main cells and the monitor cell are stacked in this component. Each of the main cells is electrically connected in a series. The monitor cell has the same structure as the main cells.

Figure 3(c) shows the configuration of the external circuit, which includes a charging/discharging controller, a DC supply (MATSUSADA PQ-20-60), a switcher, and a load. First, the RFB is charged by the DC supply. The controller switches the circuit at the moment when the total voltage of the main cells reaches the threshold. The RFB is connected to the load for starting discharge. The current changes from $-50 \mathrm{~A}$ to $50 \mathrm{~A}$ instantly.

Figures $4(\mathrm{a})$ and (b) show the total voltage of the main cells $\left(V_{\text {main }}\right)$ and the voltage of the monitor cell $\left(V_{\text {monitor }}\right)$. The monitor cell switches its mode from charging to discharging. At the instant, there appears a delay of response to the main cell.

The averaged voltage of the main cells $\left(V_{\text {main }} / m\right)$ is shown with being compared to the voltage of the monitor cell $\left(V_{\text {monitor }}\right)$ in figures $4(\mathrm{c})$ and $(\mathrm{d})$. The difference between $V_{\text {main }} / m$ and $V_{\text {monitor }}$ is denoted as $\Delta V$. Stepping change of $\Delta V$ is expected to follow equation (8). However, it behaves according to a first-order lag system in figure (4). The similar behavior of the $\Delta V$ has been observed. Conventionally, the activation polarization and the concentration polarization used to be considered at the transient behavior [28]. However, the $\Delta V$ curve is assumed to be derived from the fluid circuit in this paper, because we focus on the delay derived from the fluid circuit. 


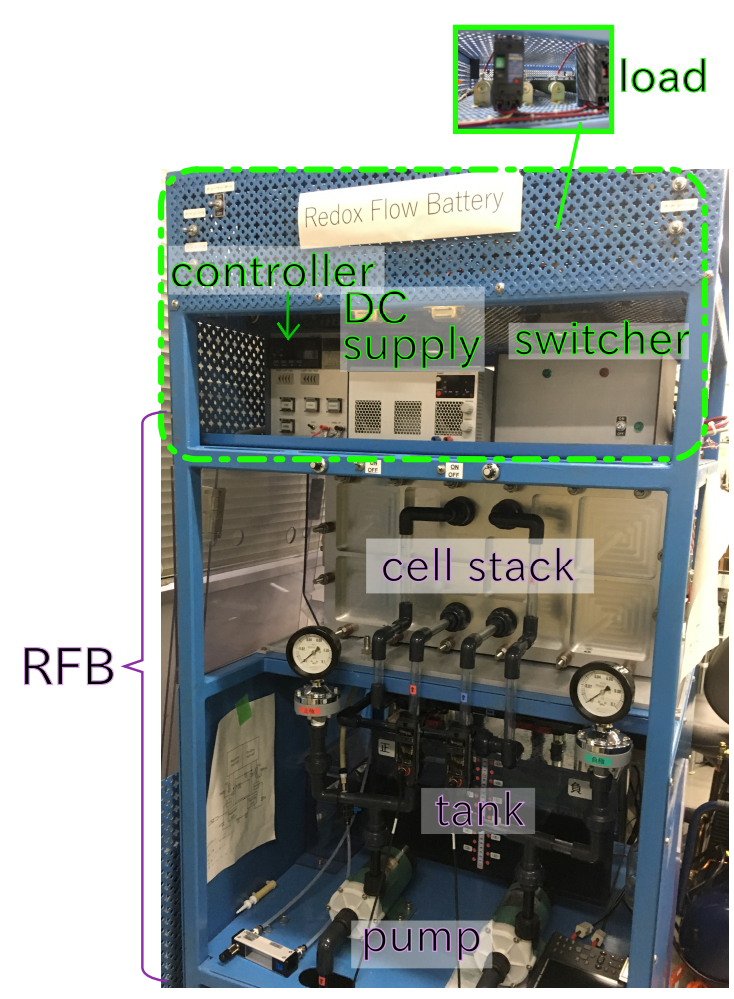

(a) Photo of tested system.

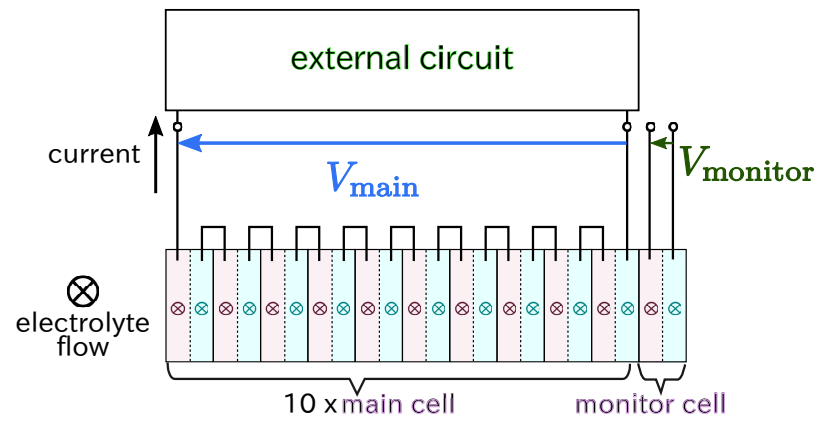

(b) Configuration of cell stack.

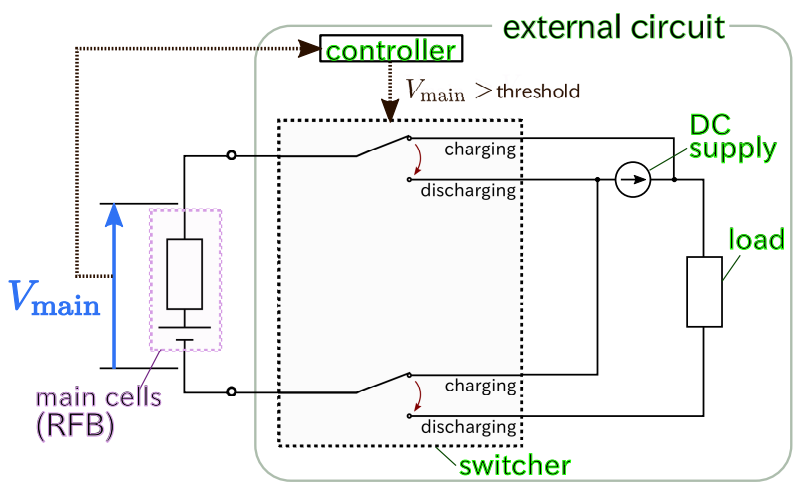

(c) Configuration of external circuit.

Figure 3. Tested system. (a) Photo of tested system. (b) Configuration of cell stack. The cell stack consists of 10 main cells and 1 monitor cell. The main cells are connected electrically in series and loaded. The monitor cell has no load. The electrolytes flow into cells through the parallel connection. (c) Configuration of external circuit with RFB. The DC supply (MATSUSADA PQ-20-60) and the load enable the RFB to charge/discharge for fixed current. First, the RFB is charged by the DC supply. When the voltage of the main cell reaches the threshold, the circuit is switched by the controller. Then the RFB begins to discharge.

It can be concluded that the assumption (6) is denied by the delays which appear in the voltages of the cells. The delays imply the appearance of the mass transport via the pipes in the voltages.

\section{Model with transport delay}

\subsection{Representation of transport delay using DDE}

This section introduces the model to describe the charging/discharging dynamics with the transport delay. The modeling is fundamentally based on the idea of Li et al. [11]. We introduce the time evolution of the ion concentration in the cells. The time evolution is represented by the DDEs which include a transport delay as the time delay.

The DDEs are derived from the mass-balance equations of $\mathrm{V}^{2+}$ in the main cell. Here, $\mathrm{V}^{2+}$ is assumed to be distributed uniformly in each cell. The current in the external circuit will obey Faraday's law [25]; hence, the rate of the reaction (1) becomes 


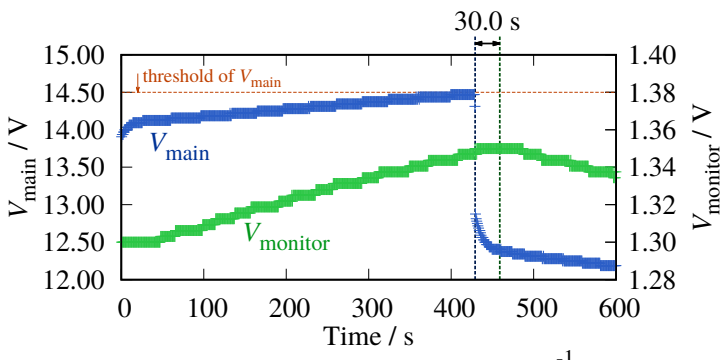

(a) Voltage at $W_{\mathrm{c}} \times(m+1)=3.3 \mathrm{~L} \mathrm{~min}^{-1}$.

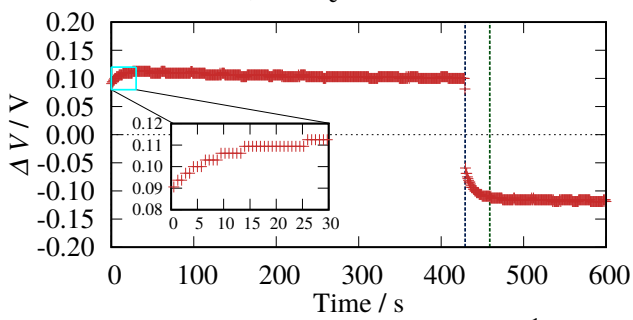

(c) $\Delta V$ at $W_{\mathrm{c}} \times(m+1)=3.3 \mathrm{~L} \mathrm{~min}^{-1}$.

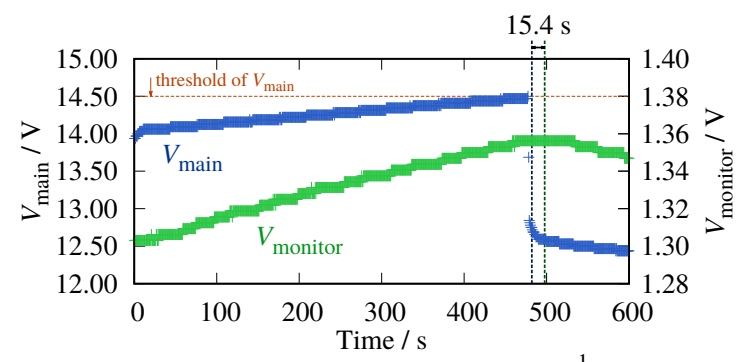

(b) Voltage at $W_{\mathrm{c}} \times(m+1)=5.5 \mathrm{~L} \mathrm{~min}^{-1}$.

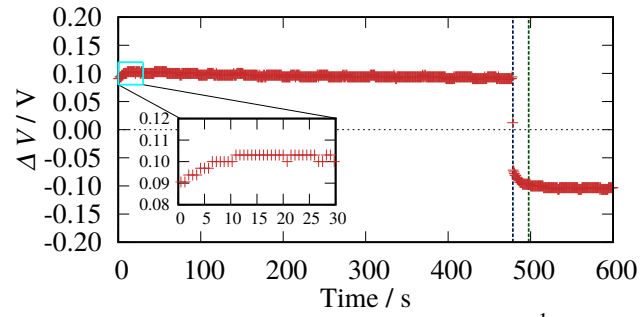

(d) $\Delta V$ at $W_{\mathrm{c}} \times(m+1)=5.5 \mathrm{~L} \mathrm{~min}^{-1}$.

Figure 4. Voltages of cells in experiment. (a), (b) Voltages of main cells and monitor cell. The monitor cell switches its operational mode with a delay of $30.0 \mathrm{~s}$ or $15.4 \mathrm{~s}$ to main the cell. (c), (d) Difference between the average voltage of the main cells and the voltage of the monitor cell $\left(\Delta V=V_{\text {main }} / m-V_{\text {monitor }}\right) . m$ is the number of main cells. A delay like a first-order lag appears at the beginning.

proportional to the current. Let us set a condition as follows.

(A) Ions stay in the tanks in a time duration $\tau_{\mathrm{d}}$.

This condition corresponds to the case of electrolytes, which flow into the cells at $t=t_{0}$, staying in the tank until $t=t_{0}-\tau_{\mathrm{d}} . \tau_{\mathrm{d}}$ is the deadtime in the transfer of electrolytes from the tanks to the cells.

The mass-balance equations in the cells and the RFB are written as follows.

$$
\begin{aligned}
\frac{\mathrm{d} c_{\text {main }}(t)}{\mathrm{d} t} & =-\frac{I(t)}{\alpha_{\mathrm{c}} F}+\frac{W_{\mathrm{c}}}{\alpha_{\mathrm{c}}}\left\{c_{\text {tank }}\left(t-\tau_{\mathrm{d}}\right)-c_{\text {main }}(t)\right\} \\
\frac{\mathrm{d} c_{\text {monitor }}(t)}{\mathrm{d} t} & =\frac{W_{\mathrm{c}}}{\alpha_{\mathrm{c}}}\left\{c_{\text {tank }}\left(t-\tau_{\mathrm{d}}\right)-c_{\text {monitor }}(t)\right\} \\
\frac{\mathrm{d} N(t)}{\mathrm{d} t} & =-\frac{m I(t)}{F}
\end{aligned}
$$

The first term in equation (9) denotes the rate of the reaction (1). The other term represents the flow of ions in the main cell. $N(t)$ is the amount of $\mathrm{V}^{2+}$ in the RFB, which is given by equation (12).

$$
N(t)=m \alpha_{\mathrm{c}} c_{\text {main }}(t)+\alpha_{\mathrm{c}} c_{\text {monitor }}(t)+\alpha_{\mathrm{t}} c_{\mathrm{tank}}(t)
$$

The DDEs of $c_{\text {main }}$ and $c_{\text {monitor }}$ are derived from equations (9)-(12).

$$
\begin{aligned}
\frac{\mathrm{d}^{2} c_{\text {main }}(t)}{\mathrm{d} t^{2}}= & -\frac{W_{\mathrm{c}}}{\alpha_{\mathrm{c}}} \frac{\mathrm{d} c_{\text {main }}(t)}{\mathrm{d} t}-\frac{m W_{\mathrm{c}}}{\alpha_{\mathrm{t}}} \frac{\mathrm{d} c_{\text {main }}\left(t-\tau_{\mathrm{d}}\right)}{\mathrm{d} t} \\
& -\frac{W_{\mathrm{c}}}{\alpha_{\mathrm{t}}} \frac{\mathrm{d} c_{\text {monitor }}\left(t-\tau_{\mathrm{d}}\right)}{\mathrm{d} t}-\frac{m W_{\mathrm{c}} I\left(t-\tau_{\mathrm{d}}\right)}{\alpha_{\mathrm{c}} \alpha_{\mathrm{t}} F}-\frac{1}{\alpha_{\mathrm{c}} F} \frac{\mathrm{d} I(t)}{\mathrm{d} t}
\end{aligned}
$$




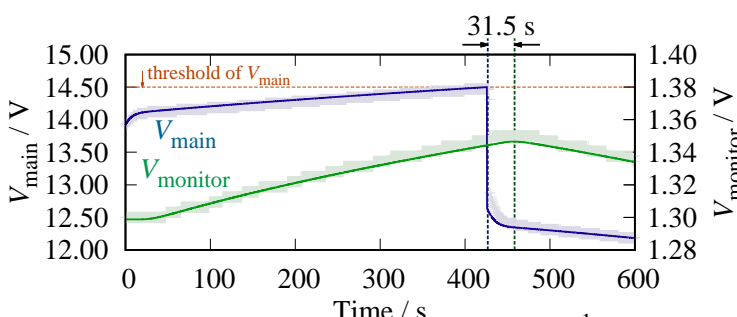

(a) Voltage at $W_{\mathrm{c}} \times(m+1)=3.3 \mathrm{~L} \mathrm{~min}^{-1}$.

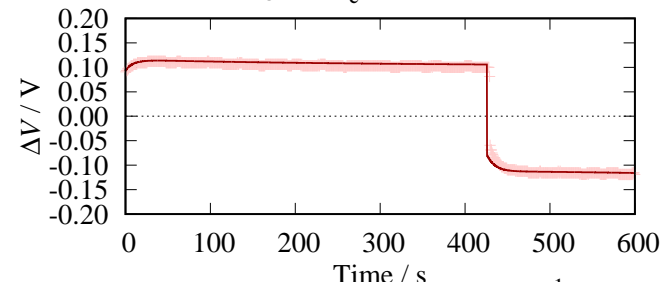

(c) $\Delta V$ at $W_{\mathrm{c}} \times(m+1)=3.3 \mathrm{~L} \mathrm{~min}^{-1}$

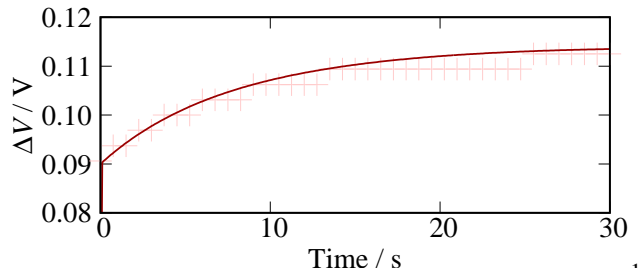

(e) Enlarged view of $\Delta V$ at $W_{\mathrm{c}} \times(m+1)=3.3 \mathrm{~L} \mathrm{~min}^{-1}$.

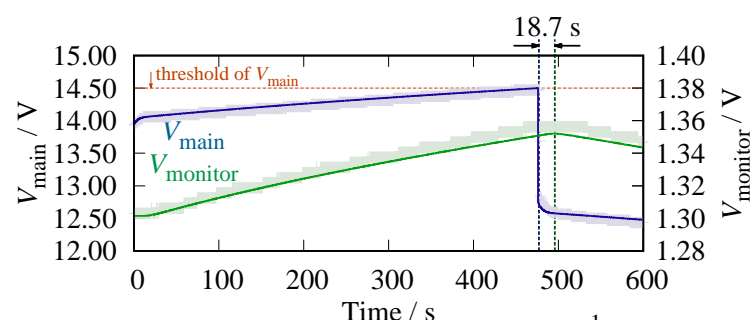

(b) Voltage at $W_{\mathrm{c}} \times(m+1)=5.5 \mathrm{~L} \mathrm{~min}^{-1}$.

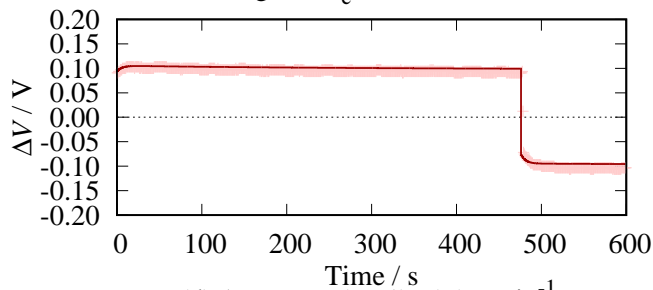

(d) $\Delta V$ at $W_{\mathrm{c}} \times(m+1)=5.5 \mathrm{~L} \mathrm{~min}^{-1}$

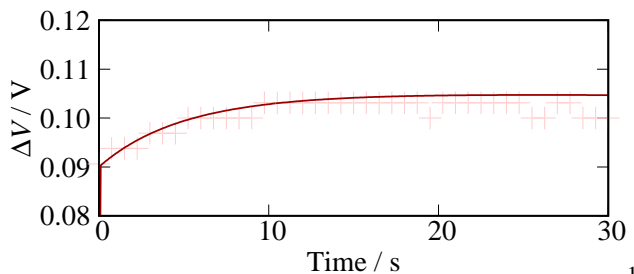

(f) Enlarged view of $\Delta V$ at $W_{\mathrm{c}} \times(m+1)=5.5 \mathrm{~L} \mathrm{~min}^{-1}$.

Figure 5. Voltages of cells in simulation with the proposed model. The simulation result (line) is compared to the experimental result (dots). (a), (b) Voltages of the main cells and monitor cell ( $\left.V_{\text {main }}, V_{\text {monitor }}\right)$. The delay in the mode switching $(31.5 \mathrm{~s}$ and $18.7 \mathrm{~s}$ ) appear in the switching of the operation. (c), (d) Difference between average voltage of main cells and voltage of monitor cell $\left(\Delta V=V_{\text {main }} / m-V_{\text {monitor }}\right)$. (e), (f) Enlarged view of $\Delta V$.

$$
\begin{aligned}
\frac{\mathrm{d}^{2} c_{\text {monitor }}(t)}{\mathrm{d} t^{2}}= & -\frac{W_{\mathrm{c}}}{\alpha_{\mathrm{c}}} \frac{\mathrm{d} c_{\text {monitor }}(t)}{\mathrm{d} t}-\frac{m W_{\mathrm{c}}}{\alpha_{\mathrm{t}}} \frac{\mathrm{d} c_{\text {main }}\left(t-\tau_{\mathrm{d}}\right)}{\mathrm{d} t} \\
& -\frac{W_{\mathrm{c}}}{\alpha_{\mathrm{t}}} \frac{\mathrm{d} c_{\text {monitor }}\left(t-\tau_{\mathrm{d}}\right)}{\mathrm{d} t}-\frac{m W_{\mathrm{c}} I\left(t-\tau_{\mathrm{d}}\right)}{\alpha_{\mathrm{c}} \alpha_{\mathrm{t}} F}
\end{aligned}
$$

$\mathrm{d} I(t) / \mathrm{d} t=0$ in this paper.

The voltages of the main cells and the monitor cell are determined by $c_{\text {main }}$ and $c_{\text {monitor }}$ based on the Nernst equation (5).

$$
V_{\text {main }}(t)=m\left\{g\left(c_{\text {main }}(t)\right)-r I\right\}, \quad V_{\text {monitor }}(t)=g\left(c_{\text {monitor }}(t)\right)
$$

The simulation result is obtained by solving DDEs (13) and (14) with Runge-Kutta fourth order method [29]. The time step is fixed at 0.1s. Memory is prepared to hold the values, which are used as the delay terms in DDEs (13) and (14). The memory holds the initial values in $t \leq t_{\mathrm{d}}$.

Figure 5 shows the result of simulation. This model reproduces both of the delay in the mode switching and the $\Delta V$ curve.

The model has three fitting parameters; $\alpha_{\mathrm{c}}, \alpha_{\mathrm{t}}$, and $\tau_{\mathrm{d}} . \alpha_{\mathrm{c}}$ and $\alpha_{\mathrm{t}}$ are the volumes of electrolytes in the cells and the tanks. $\alpha_{\mathrm{c}}$ and $\alpha_{\mathrm{t}}$ in table 3 are smaller than the volume of cells, and the tanks in table 2. Moreover, the parameter $\alpha_{\mathrm{t}}$ depends on the 
Table 3. Parameters for simulations.

\begin{tabular}{c|c|c|c}
\hline$W_{\mathrm{c}} \times(m+1)$ & Flow rate of electrolyte & $3.3 \mathrm{~L} \mathrm{~min}^{-1}$ & $5.5 \mathrm{~L} \mathrm{~min}^{-1}$ \\
$\alpha_{\mathrm{t}}$ & Volume of electrolyte in tank & $8.74 \mathrm{~L}$ & $8.44 \mathrm{~L}$ \\
$\alpha_{\mathrm{c}}$ & Volume of electrolyte in cell & $0.045 \mathrm{~L}$ & $0.045 \mathrm{~L}$ \\
$\tau_{\mathrm{d}}$ & Time delay & $19 \mathrm{~s}$ & $15 \mathrm{~s}$ \\
$r$ & Internal resistance (charging) & $0.0018 \Omega$ & $0.0018 \Omega$ \\
$r$ & Internal resistance (discharging) & $0.0019 \Omega$ & $0.0019 \Omega$ \\
\hline
\end{tabular}

flow rate of the electrolyte. The dead space [30] in the RFB is considered to be in the smaller volume of electrolytes in the model. $\tau_{\mathrm{d}}$ is expected to depend on the flow rate of the electrolytes considering condition $(\mathrm{A})$. As a result, $\tau_{\mathrm{d}}$ is adjusted at $19 \mathrm{~s}$ for $W_{\mathrm{c}} \times(m+1)=3.3 \mathrm{~L} \mathrm{~min}^{-1}$ and $15 \mathrm{~s}$ for $W_{\mathrm{c}} \times(m+1)=5.5 \mathrm{~L} \mathrm{~min}^{-1} . \tau_{\mathrm{d}}$ definitely varies with the flow rate of the electrolyte.

\subsection{Analysis of two kinds of delays}

This section discusses the two kinds of delays appeared in the voltages of the cells in figure 4 under the proposed model.

Figure 6 shows the dependence of the simulation on the time delay. The flow rate of the electrolyte is fixed at $W_{\mathrm{c}} \times(m+1)=3.3 \mathrm{Lmin}^{-1}$. Charging time and the mode switching is precisely simulated by accepting the time delay. The $\Delta V$ curve appears regardless of the time delay via the pipes. The transfer of ions in the cells is considered to appears as the $\Delta V$ curve.

At the beginning of charging or discharging, $\Delta V$ curves as the first-order lag response from the model equations (13)-(15). $\Delta V(t)$ can be linearized as following equations (16) (ref. Appendix A).

$$
\Delta V(t) \approx g^{\prime}\left(c_{0}\right) \Delta c(t)-r I, \Delta c(t)=c_{\text {main }}(t)-c_{\text {monitor }}(t)
$$

The time evolution of $\Delta c(t)$ does not include the time delay $\tau_{\mathrm{d}}$ as following ODE (17).

$$
\frac{\mathrm{d}^{2}(\Delta c(t))}{\mathrm{d} t^{2}}=-\frac{W_{\mathrm{c}}}{\alpha_{\mathrm{c}}} \frac{\mathrm{d}(\Delta c(t))}{\mathrm{d} t}-\frac{1}{\alpha_{\mathrm{c}} F} \frac{\mathrm{d} I(t))}{\mathrm{d} t}
$$

The ODE (17) is obtained by taking the difference between DDEs (13) and (14). The solution of ODE (17) is analytically obtained for $\mathrm{d} I(t) / \mathrm{d} t=0 \mathrm{~A} \mathrm{~s}^{-1}$ as follows.

$$
\Delta c(t)=-\frac{I(t)}{W_{\mathrm{c}} F}\left(1-\mathrm{e}^{-\frac{W_{\mathrm{c}}}{\alpha_{\mathrm{c}}} t}\right)
$$

The analytic solution (18) shows that $\Delta c$ approaches a constant value $\Delta c=-I(t) / W_{\mathrm{c}} F$ within the time constant $\tau_{\mathrm{c}}=\alpha_{\mathrm{c}} / W_{\mathrm{c}} . \Delta V(t)$ is rescaled by $\tau_{\mathrm{c}}=\alpha_{\mathrm{c}} / W_{\mathrm{c}}$ as follows.

$$
\Delta V(t)=-g^{\prime}\left(c_{0}\right) \frac{I(t)}{W_{\mathrm{c}} F}\left(1-\mathrm{e}^{-\frac{t}{\tau_{\mathrm{c}}}}\right)-r I(t)
$$

$\tau_{\mathrm{c}}$ depends on the flow rate of electrolyte. 


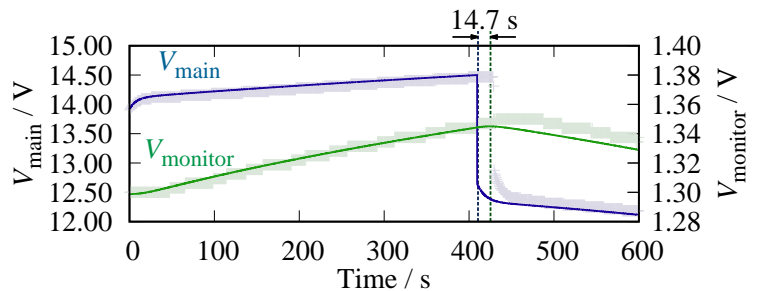

(a) Voltage for $\tau_{\mathrm{d}}=0 \mathrm{~s}$.

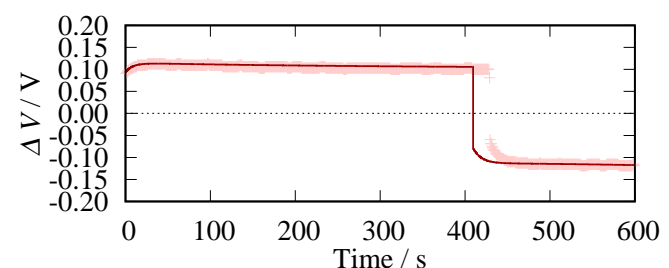

(c) $\Delta V$ for $\tau_{\mathrm{d}}=0 \mathrm{~s}$

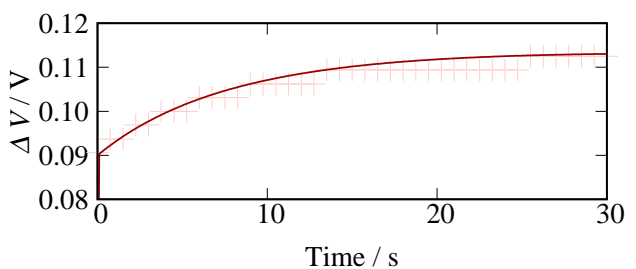

(e) Enlarged view of $\Delta V$ for $\tau_{\mathrm{d}}=0 \mathrm{~s}$.

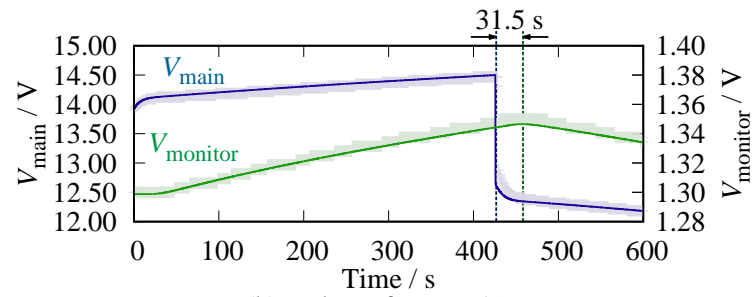

(b) Voltage for $\tau_{\mathrm{d}}=19 \mathrm{~s}$.

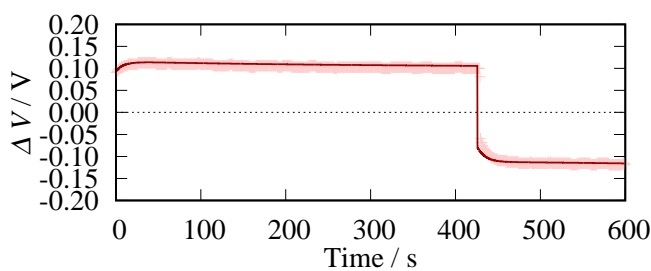

(d) $\Delta V$ for $\tau_{\mathrm{d}}=19 \mathrm{~s}$.

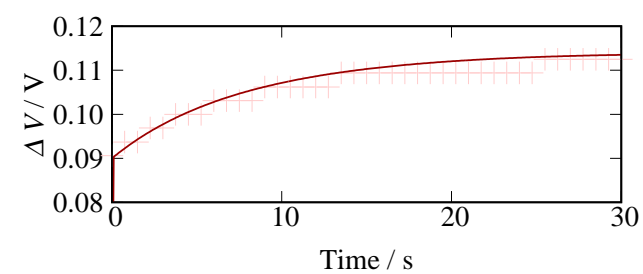

(f) Enlarged view of $\Delta V$ for $\tau_{\mathrm{d}}=19 \mathrm{~s}$.

Figure 6. Dependence of the simulation result on the time delay. The lines show the simulation result and dots are given from the experiment. (a), (b) Voltages of the main cells and monitor cell. The delay in the mode switching (14.7 s and $31.5 \mathrm{~s}$ ). (c), (d) Difference between average voltage of main cells and voltage of monitor cell ( $\left.\Delta V=V_{\text {main }} / m-V_{\text {monitor }}\right)$. (e), (f) Enlarged view of $\Delta V$.

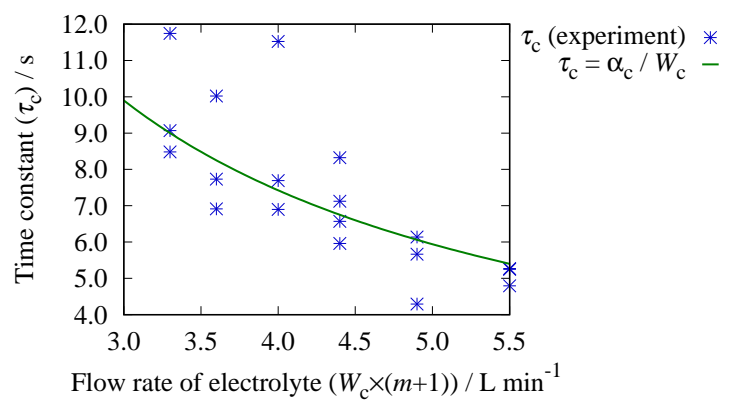

Figure 7. Flow dependence of time constant $\tau_{\mathrm{c}}$. The time constant characterizes the transient behavior of $\Delta V$ at the beginning of charging. Here $\Delta V$ is the difference between the average voltage of the main cells and the voltage of the monitor cell. The line was obtained by $\tau_{\mathrm{c}}\left(=\alpha_{\mathrm{c}} / W_{\mathrm{c}}\right)$, where $\alpha_{\mathrm{c}}$ is the volume of the electrolyte in a cell. $\alpha_{\mathrm{c}}$ is set at $0.045 \mathrm{~L}$ in the simulation. The dots are extracted by fitting the approximation of $\Delta V$ to the experimental data.

Figure 7 verifies the dependence of the $\tau_{\mathrm{c}}$ on the flow rate of the electrolyte. The theoretically obtained $\tau_{\mathrm{c}}$ are evaluated by the solid line of $\tau_{\mathrm{c}}=\alpha_{\mathrm{c}} / W_{\mathrm{c}}$. When approximation (19) fits $\Delta V$ in the experimental data, $\tau_{\mathrm{c}}$ is extracted as a parameter of approximation (19). The dots show the extracted value. The flow dependence of the 
extracted $\tau_{\mathrm{c}}$ is similar to its theoretical prediction. The similarity corresponds to the $\Delta V$ which appears due to the move of the ions in the cells.

\section{Conclusion}

This paper proposed the dynamical model of the RFB including the transport delay of the ions via the pipes. This model is derived by considering the mass transport via the pipes. The simulation explains the results corresponding to the experiment.

The proposed model is physically reasonable both in steady state and at the transient state. The fluid circuit can be evaluated with fitting parameters of the proposed model. In particular, the model clarifies the length of the transport delay which governs the dynamics. Moreover, the volume of the electrolytes in the model implies the effective volume in the charging/discharging dynamics. It will be an essential indicator for evaluating the circulation system of the electrolyte in the RFB. If the effect of the fluid circuit on the dynamics is physically analyzed with the proposed model, the analysis offers a direction of the development for the dynamic flow control system with considering the delay.

\section{Acknowledgment}

This research was supported by Super Cluster Program from Japan Science and Technology Agency. And the test system is provided by Sumitomo Electric Industries, Ltd.

\section{Appendix A. Evaluation of approximation}

The OCV of a cell is given by a function $g(c) \cdot g(c)$ is linearized in the neighborhood of $c_{i}=c_{0}(i=$ main, monitor $)$ as following equation (A.1).

$$
\begin{aligned}
E_{\mathrm{e}} & =g(c) \\
& =g\left(c_{0}\right)+g^{\prime}\left(c_{0}\right)\left(c-c_{0}\right)+\mathcal{O}\left(c-c_{0}\right)^{2} \\
& \approx g^{\prime}\left(c_{0}\right) c+g\left(c_{0}\right)+g^{\prime}\left(c_{0}\right) c_{0}
\end{aligned}
$$

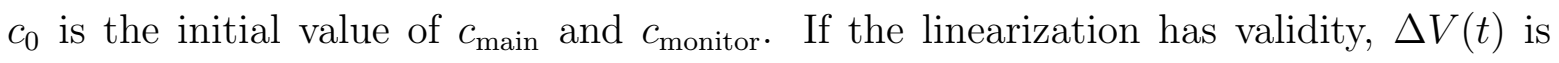
represented by the approximation as follows.

$$
\begin{aligned}
\Delta V(t)= & g\left(c_{\text {main }}(t)\right)-r I(t)-g\left(c_{\text {monitor }}(t)\right) \\
\approx & \left\{g^{\prime}\left(c_{0}\right) c_{\text {main }}(t)+g\left(c_{0}\right)+g^{\prime}\left(c_{0}\right) c_{0}\right\}-r I(t) \\
& \quad-\left\{g^{\prime}\left(c_{0}\right) c_{\text {monitor }}(t)+g\left(c_{0}\right)+g^{\prime}\left(c_{0}\right) c_{0}\right\} \\
= & g^{\prime}\left(c_{0}\right)\left(c_{\text {main }}(t)-c_{\text {monitor }}(t)\right)-r I(t)
\end{aligned}
$$

Approximation (A.2) is compared to the model which is proposed in section 3.1 in figure A1. Figure A1 shows the error of the approximation compared to the simulation result. The time is rescaled as $\tau_{\mathrm{c}}=\alpha_{\mathrm{c}} / W_{\mathrm{c}}$. The error is over 0.01 after $\tau=0.5$. Thus, $\tau_{\mathrm{c}}$ should be extracted from the voltage data within $t=\tau_{\mathrm{c}} / 2$ after the beginning of charging. 

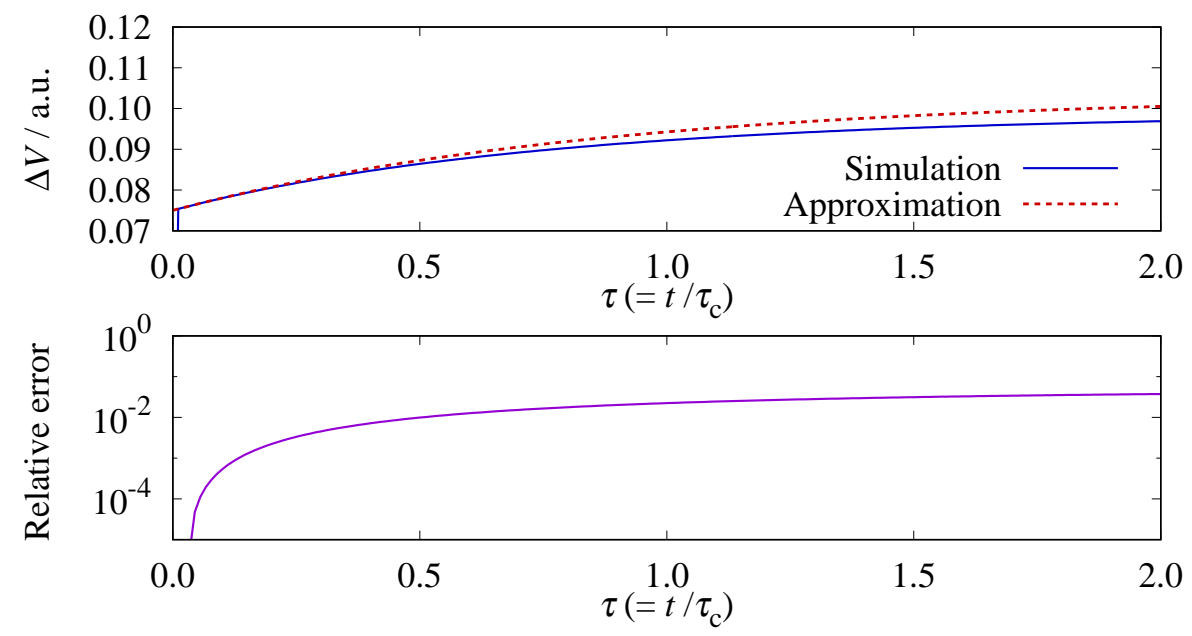

Figure A1. Approximation error. The error is calculated by the ratio of the absolute error to the simulation $(\Delta V) . \tau$ is the rescaled time with $\tau_{\mathrm{c}}=9.0 \mathrm{~s}$.

\section{References}

[1] Skyllas-Kazacos M, Rychcik M, Robins R G, Fane A G and Green M A 1986 New all-vanadium redox flow cell Journal of the Electrochemical Society 133 1057-1058

[2] Molina M G 2017 Energy storage and power electronics technologies: A strong combination to empower the transformation to the smart grid Proceedings of the IEEE 105 2191-2219

[3] Skyllas-Kazacos M, Chakrabarti M H, Hajimolana S A, Mjalli F S and Saleem M 2011 Progress in flow battery research and development Journal of The Electrochemical Society 158 R55-R79

[4] Kaizuka T and Sasaki T 2001 Evaluation of control maintaining electric power quality by use of rechargeable battery system 2001 IEEE Power Engineering Society Winter Meeting pp 88-93

[5] Shigematsu T, Kumamoto T, Deguchi H and Hara T 2002 Applications of a vanadium redox-flow battery to maintain power quality IEEE/PES Transmission and Distribution Conference and Exhibition vol 2 pp 1065-1070

[6] Joerissen L, Garche J, Fabjan C and Tomazic G 2004 Possible use of vanadium redox-flow batteries for energy storage in small grids and stand-alone photovoltaic systems Journal of Power Sources $12798-104$

[7] Ma X, Zhang H, Sun C, Zou Y and Zhang T 2012 An optimal strategy of electrolyte flow rate for vanadium redox flow battery Journal of Power Sources 203 153-158

[8] Yoshimoto K, Nanahara T, Koshimizu G and Uchida Y 2006 New control method for regulating state-of-charge of a battery in hybrid wind power/battery energy storage system 2006 IEEE PES Power Systems Conference and Exposition pp 1244-1251

[9] Li Y, Zhang X, Bao J and Skyllas-Kazacos M 2017 Studies on optimal charging conditions for vanadium redox flow batteries Journal of Energy Storage 11 191-199

[10] Zheng Q, Li X, Cheng Y, Ning G, Xing F and Zhang H 2014 Development and perspective in vanadium flow battery modeling Applied Energy 132 254-266

[11] Li M and Hikihara T 2008 A coupled dynamical model of redox flow battery based on chemical reaction, fluid flow, and electrical circuit IEICE Transactions on Fundamentals of Electronics, Communications and Computer Sciences E91-A 1741-1747

[12] Li Y, Skyllas-Kazacos M and Bao J 2016 A dynamic plug flow reactor model for a vanadium redox flow battery cell Journal of Power Sources 311 57-67

[13] Shah A A, Watt-Smith M J and Walsh F C 2008 A dynamic performance model for redox-flow batteries involving soluble species Electrochimica Acta $\mathbf{5 3}$ 8087-8100 
[14] Mannari T and Hikihara T 2018 Transient behavior of redox flow battery connected to circuit based on global phase structure Nonlinear Theory and Its Applications, IEICE 9 137-147

[15] Mahmoud M S 2010 Switched Time-Delay Systems (Springer Bostan) chap 3

[16] Li M 2011 Fundamental research about dynamical model of redox flow battery based on chemical reaction (in Japanese) Ph.D. thesis Kyoto University

[17] Bendtsen J, Val J, Carsten Kallesø e and Krstic M 2017 Control of district heating system with flow-dependent delays IFAC-PapersOnLine 50 13612-13617

[18] Zeng X and Wang J 2014 A physics-based time-varying transport delay oxygen concentration model for dual-loop exhaust gas recirculation (egr) engine air-paths Applied Energy 125 300-307

[19] Hale J K and Verduyn Lunel S M 2001 Effects of small delays on stability and control Operator Theory and Analysis (Springer Basel AG) pp 275-301

[20] Averina V, Kolmanovsky I, Gibson A, Song G and Bueler E 2005 Analysis and control of delaydependent behavior of engine air-to-fuel ratio Proceedings of 2005 IEEE Conference on Control Applications, 2005. CCA 2005. pp 1222-1227

[21] Erneux T 2009 Applied Delay Differential Equations (Springer-Verlag New York) chap 1

[22] Theodore L 2012 Chemical reactor analysis and applications for the practicing engineer (John Wiley \& Sons) chap 7

[23] Shibata T, Kumamoto T, Nagaoka Y, Kawase K and Yano K 2013 Redox flow batteries for the stable supply of renewable energy SEI Technical review $\mathbf{7 6}$ 14-22

[24] Li M H, Funaki T and Hikihara T 2007 A study of output terminal voltage modeling for redox flow battery based on charge and discharge experiments 2007 Power Conversion Conference Nagoya pp 221-225

[25] Wang J 2006 Analytical electrochemistry (John Wiley \& Sons) chap 1 3rd ed

[26] Ressel S, Bill F, Holtz L, Janshen N, Chica A, Flower T, Weidlich C and Struckmann T 2018 State of charge monitoring of vanadium redox flow batteries using half cell potentials and electrolyte density Journal of Power Sources 378 776-783

[27] Sukkar T and Skyllas-Kazacos M 2003 Water transfer behaviour across cation exchange membranes in the vanadium redox battery Journal of Membrane Science 222 235-247

[28] Mohamed M R, Ahmad H, Seman M N A, Razali S and Najib M S 2013 Electrical circuit model of a vanadium redox flow battery using extended kalman filter Journal of power sources 239 284-293

[29] Press W H, Teukolsky S A, Vetterling W T and Plannery B P 1992 Numerical Recipes in C (Cambridge University Press) pp 710-714

[30] Haeger A, Forrestal C, Xu P and Ren Z J 2014 High performance spiral wound microbial fuel cell with hydraulic characterization Bioresource Technology 174 287-293 